\title{
Pre and Post Training Perceptions Towards School Leadership: A Case of Haramaya University Second Entry Primary School Female Principal Trainees
}

\author{
Dibekulu Alem Asegu \\ PhD. Fellow at Bahir Dar University in Educational Leadership and Policy.
}

\begin{abstract}
This study aimed at assessing female primary school leadership trainees towards school leadership and the expected challenges in leadership activities. The study employed pre-post quazi-experimental design. Female primary school leadership trainees and assigned trainers for the courses were participants of the study. Data were gathered through questionnaires (pre and post), interviews, documents (report). The findings indicated that there was a statistically significant increase in perceiving school leadership positively from pre training test $(\mathrm{M}=2.29$, $\mathrm{SD}=0.59)$ to post training $(\mathrm{M}=4.38, \mathrm{SD}=0.48), \mathrm{t}(79)=24.85, \mathrm{p}<0.05$ (two-tailed). The mean increase in pre-post training was 2.09 with a $95 \%$ confidence interval ranging from 2.29 to 4.38 . In addition the perceived challenges there was statistically significant decrease in perceiving leadership activities in post training challenges $(\mathrm{M}=3.63$, $\mathrm{SD}=0.66)$ to pretest training challenges $(\mathrm{M}=2.22, \mathrm{SD}=0.56), \mathrm{t}(79)=15.27, \mathrm{p}<0.05$. The mean difference between pre-post training challenges is (1.40) with a 95\% confidence interval ranging from 3.63 to 2.22 . Interview results and reports of trainees also ensured that as there was perception change of trainees because of the training provided. Thus it is possible to conclude that the training provided for female primary school leadership trainees was important and addressed the intended goals of the training.
\end{abstract}

Keywords: Pre and post training, perception towards school leadership, female principals

DOI: $10.7176 / \mathrm{JEP} / 10-7-05$

Publication date:March $31^{\text {st }} 2019$

\section{INTRODUCTION}

\subsection{Background of the Study}

Leadership has been defined in terms of traits, behaviors, influences, interaction patterns, role relationships, and occupation of a position. After a comprehensive review of the leadership literature, Stogdill (1974, p.259) concluded that "there are almost as many definitions of leadership as there are persons who have attempted to define the concept." For Hersey and Blanchard, (1982, p. 83), "leadership is interpersonal influence exercised in a situation and directed, through the communication process, toward the attainment of a specialized goal or goals". According to Bass, (1985) it is an interaction between members of a group. In general, leadership is influencing others to act for the achievement of organizational objectives.

Leadership in schools is somewhat different. Schools are places where its outcomes are multifaceted and only some are relatively easy to measure (Busher, 2006). In schools group of people, children and adults, who are legally bound together for the purposes of learning and teaching. Whatever the size of the group, in order for that learning and teaching to happen in a useful and constructive way, some people must take responsibility ( leaders) for ensuring that the others (followers) are resourced, supported and enabled to work as well as possible which is the concern of educational leadership (Gold, 2000). Educational leadership is a long-term campaign it grows out of knowledge, of experience and requires patience and much time, and its leadership can be enjoyed only in the long run (Pele, 2012).

As to Rimmer (2003), school leadership is the most important activity next to class room instruction to improve students' learning. In addition to this, D'Souza (1994), explained that leaders who has initiative to start things and keep them alive, open minded, welcomes the ideas of others and acts with understanding toward suggestions, and tactful are some qualities of school leaders. Schools leaders who are effective are successful in their activities while schools leads by ineffective principals are full of instability, disorder and improper teaching and learning process. School effectiveness is the outcome of the capacity of a transformational leader (Hoyle and Wallace, 2005).

Here the question is being female or male has a difference in leading schools? Or is there any significance difference between male and female principals in carrying out educational activities? Initial research, largely influenced by feminist scholars, found little differences in the leadership styles of male and female managers, suggesting that the actual behavior of women at administrative jobs was strongly influenced by executive role models that seemed to claim for masculinity (Henning and Jardim, 1978 cited in Melero, 2004).

Historically, in most of the world countries, men had been running the leadership career in any of organization including educational institutions. Holtkamp (2002) notes that leadership roles have been held by men. In most societies, now and then, females playing traditional role of home makers while males remaining a leader in every 
sphere of life (Craig et al., 1996; Giddens, 2005). Because of this social attitude females have been reluctant to pursue educational, administrative positions (Holtkamp, 2002). The disproportionate representation of women in educational administration is certainly not a new phenomenon, but it is one that has gained some recognition as a contemporary educational issue in the last decade (Pearman, 1999). Some research findings and surveys in the global context suggest that the proportion of females in professional and managerial position is slowly increasing than before (Giddens, 2005; Holtkamp, 2002).

In our country Ethiopia, the dominance of males in leadership positions seems stayed as culture and still it is influencing the representation of females to remain and proceed in dilatory manner. However, women's participation at various levels of executive councils and administrative bodies has been increasing. The same is true for an increment of women number in federal and regional House of Representatives. On the other hand, school administration has been male dominated as a result the government has set a plan to increase the number of model students \&teachers in schools as well as appointing those able women at leadership position (MoWA, 2006).

As stated in ESDP V (MOE, 2015) refereeing to the education and training policy frame work of the country amongst the priorities set is promoting effective leadership, management and governance at all levels. In this regard, a number of school principals has been trained and assigned in schools. However, females didn't get special attention to come to the position expect the provision of mere opportunities for them. As reported by (MOE, 2017), females school leaders were about 8\% till 2017 at the start of ESDP V. This indicates that there is big discrepancy compared to males.

Currently, the government of Ethiopia seems initiated to increase the number of female school leaders. As a result primary female school leadership training is started since 2017 in some selected universities of the country. In the first round of the training 1024 females has been trained and assigned as primary school principals. Form these, 193 of the trainees were placed in at Haramaya University of which 186 have attended and completed the training. Continuing this training the Ministry of Education planned to train [3480] females for the same purpose which will increase their representation from $12.3 \%$ to $21.9 \%$ in school leadership position (MOE, 2018). It is believed; this will bring national growth of females' school leadership position however still it needs a big deal for further improvement in primary schools as well as in secondary schools.

With this end, this study was focused on female primary school principals trainees assigned at Haramaya University in 2018 aiming at assessing trainees pre and post perceptions towards school leadership and expected challenges on leadership activities.

\subsection{Statement of the Problem}

Existence in life perpetuates because of the presence of both males and females in any part of the world. Both are equally important. So why the two are labeled as one is different from the other in normal task performances regardless of their biological differences? Over the centuries, femininity has been stereotyped as dependent, submissive and conforming, and hence women have been seen as lacking in leadership qualities (Moran, 1992). The male bias is reflected in the false conception of leadership as mere command or control. Similarly Bass (1981) in Moran (1992), states that stereotypes have their effects on behavior, which enables us to expect women to be more submissive, so being in trouble to take orders from women, no matter what they are like individually. Women leaders themselves are in conflict when facing divergence in what is expected from them in their roles as managers and in their roles as females, but do these stereotypes reflect reality?

As stated by Azzah and Jones (2017), despite the predominance of perspectives on women's leadership, which consistently emphasize the underrepresentation of women in virtually every sphere of political and economic life in countries around the world. They reported that very little is known about women's leadership, especially in higher education in the Kingdom of Saudi Arabia (KSA). This is also true in other world countries like in Republic of South Africa. Studies showed that the challenges faced by female managers that hinder them from achieving true parity in relation to their male colleagues could be school related, external factors and those within the person herself (Khumalo, 2000, cited in Nzeli, 2013). Van der Westhuizen (1997) cited in Nzeli, (2013), believes that intrinsic, internal or personal barriers that influence the life of women are generally regarded as the inadequacies, which are within women because of their femaleness.

In our country Ethiopia, researches have been conducted related to females' school leadership practices, representations, challenges and related issues. Nuri (2016) reported that female teachers prefer family roles and teaching as more important than school leadership so that they have less interest and motivation to apply for school leadership position. He also found that most of the management positions in schools are still dominated by men teachers in his study area (in Guna Wereda Arsi Zone of Oromia Regional State). Similarly, Lemessa (2014), reported as higher officials make gender bias while selecting school leaders. Lack of special support to females to win competition for school leadership position, as a result they have less representation compared to males in school leadership positions in primary schools of Jimma town. However, they were strong in making decision, capable to lead primary school; and men consider women as their equal counterparts, females consider themselves 
as they are not able to lead schools successfully.

Moreover, Netsanet (2013), reported as the presence of strategies, plans, and policies, gender sensitivity of selection criteria of principals for secondary schools, regular revision of gender policies and strategies, the presence of women affair departments and presence of on-job and pre-job trainings and the effectiveness of women in planning were the opportunities identified that encouraged women's participation in school leadership. Whereas, less commitment of officials to implement gender sensitive policies, negative stereotyping, fear of balancing family and professional work, informal network of men, absence of role models and low educational background of women were barriers for the low participation of women principals in secondary schools of Addis Ababa. In addition to these, Leliftu (2014) also found that the involvement of female teachers in educational leadership seems to show insignificant increment each year in the last five years in Ilu Aba Bora Zone. Amongst the major problems mentioned are lacks confidence because of the social back ground in the culture of the community, pseudo type opportunities to gain bottom experiences in educational leadership are the major ones.

From the points raised in the above local research findings it is possible to say that females are still in problem to take part in school leadership positions although the government has taken encourage able changes starting from the policy design to setting strategies of implementation. In this study, female primary school leadership trainees' perceptions towards school leadership and expected challenges of leadership activities are assessed. Thus aim was assessing the impact of the training on trainees' perception towards school leadership focusing on female primary school principal trainees at Haramaya University in 2018.

To this end, the following leading questions were set to be answered in this study.

1. What are perceptions of primary schools female leadership trainees towards school leadership and expected challenges on leadership activities before and after training?

2. Is there any significance difference between trainees' pre and post perceptions towards school leadership and expected challenges on leadership activities?

\subsection{Objective of the Study}

\subsubsection{General Objective of the Study}

The general objective of the study was assessing the impact of female primary school principals training on their perceptions towards school leadership and the expected challenges on leadership activities.

\subsubsection{Specific Objectives of the Study}

The specific objectives designed to address throughout this study were:

* Identifying what looks like the perceptions of female primary school principal trainees towards school leadership and expected challenges on leadership activities before and after the training.

* To find out whether there is significance differences of trainees' perceptions towards school leadership and expected challenges on leadership activities before and after the training.

* To identify common perceptions and to forward possible suggestions for the effectiveness of future trainings.

\subsection{Significance of the Study}

This study might have the following significances.

* Females are as strong as males to perform tasks in the school. But they fail to come to the front with their abilities because of numerous factors. Therefore, this study may contribute to be aware of their own perceptions towards school leadership and what they consider as a challenge related to leadership activities.

* It may give invaluable information for concerned responsible bodies (MOE, REB, WEO, Universities, and trainees in relation to females' school leadership practices, problems and the way of enhancing females' participation in school leadership in the future.

* It may also enable anyone in the education sector particularly who undermine the role of females in leadership position to understand the problems to put their efforts for improvements as much as possible from the points of views of the world.

* Finally, it may be used as one source of information for further investigation in the area.

\subsection{Delimitation of the Study}

Conceptually this study was delimited on identification female primary school principal trainees' pre and post perceptions towards school leadership and their expected challenges on leadership activities. Regarding the methodology comparative case and descriptive study designs were employed. Both quantitative and qualitative method of data collection has been used to collect relevant data throughout the study. In addition to this, primary school female school leadership trainees at Haramaya University (second round entrants) were taken as a specific case. 


\subsection{Limitation of the Study}

The limitation of the study could be impossibility of making conclusions based on the findings gained in this study on the other equivalent trainees in the other universities.

\section{Research Design and Methodology of the Study 2.1 Research Design}

Pre and posttest quazi experimental design was employed for this study as this design is appropriate to explain facts of in two independent situations (pre and posttests in this case). In quazi experimental design According to Creswell (2012), pre-post provides a measure on some attribute or characteristic that we want to assess (perception towards school leadership) for participants in an experiment before and after they attend the training. Thus this design is properly chosen for the intended purpose.

\subsection{Data Source: primary and secondary}

Data were obtained from primary and secondary sources according to the need and availability. According to Kothari (1985) primary data is original information collected for the first time. Primary data sources for this study were, female school leadership trainees in 2018 at Haramaya University and assigned instructors to offer the courses for trainees from different fields and departments (EDPM, SINE, Psychology, AECD, Geography and Environmental studies, Health Sciences, Gender and developmental Studies and ICT. The secondary sources were the report presented by trainees about the training and related literatures.

\subsection{Population, Sample and Sampling Techniques}

\subsubsection{Population of the study}

This study has been conducted in Haramaya University, CEBS, depart ment of EDPM focusing female school leadership trainees in 2018 (which was offered from March 19- May, 19/2018 for three consecutive months). Within this frame of reference the population considered were the total number of female school leadership trainees registered to attend the training( $\mathrm{N}=117)$, all instructors assigned to offer the courses ( $\mathrm{N}=27)$

\subsubsection{Samples and Sampling Techniques}

As indicated in the description of the population 117 female trainees and 27 instructors assigned for the training were taken as frame of reference (targeted population). The following samples were taken from these target population.

Table 1: Respondents population, samples taken and Sampling techniques

\begin{tabular}{|l|l|l|l|l|l|l|l|l|}
\hline No & Respondents & Population & $\begin{array}{l}\text { Samples } \\
\text { taken }\end{array}$ & $\begin{array}{l}\text { Number of } \\
\text { completed } \\
\text { questionnaires and } \\
\text { retuned back/ } \\
\text { interviewed } \\
\text { instructors }\end{array}$ & $\begin{array}{l}\text { Sampling } \\
\text { techniques }\end{array}$ & $\begin{array}{l}\text { Data } \\
\text { collection } \\
\text { tool }\end{array}$ \\
\hline 1 & Trainees & 117 & 93 & 79.49 & 80 & 86.02 & $\begin{array}{l}\text { Systematic Random } \\
\text { Sampling }\end{array}$ & Questionnaire \\
\cline { 1 - 9 } & Instructors & 27 & 14 & 29.62 & 7 & 50.00 & $\begin{array}{l}\text { Random and } \\
\text { purposive sampling }\end{array}$ & Interview \\
\hline 3 & Total & 144 & 107 & 75.00 & 87 & 81.30 & & \\
\hline
\end{tabular}

\subsection{Instruments for Data Collection}

\subsubsection{Questionnaires}

After having reviewed various literatures related to leadership in general and school leadership in particular and identifying basic ideas connected with females and males in school leadership two sets of 5-point Likert-scaled type (one set on trainees' perception (15 items) and the other on expected challenges of school leadership (16 Items) were designed). Moreover, open ended items were asked at the end of the two sets.

\subsubsection{Interview}

The semi-structure interview guide was prepared ( for both trainees and trainers) and designed in the way to find out useful insights, prospects, challenges and the implemented activities related to training females for primary school principal ship.

\subsubsection{Document Analysis}

One of the document used dominantly for this study was trainees exit report presented during their graduation and discussions made with coordinator of the training program. Moreover, the local (in Ethiopian context) and from the abroad (worldwide studies) were used. 


\subsection{Data Collection Procedures and Analysis}

Questionnaires were constructed after reviewing a number of literatures to structure and design in logical manner. After designing the items used in both questionnaires and the interview items it was given for two PhD candidate students in the EDPM who presented their seminar paper in leadership relate topics to check the appropriateness of each of the items regarding content, construct and face validity. After their critical comments and correction both the questionaries' and interview items made refined and used in the proper time. Its reliability was checked using Chrobah alpha test collected from 20 female $3^{\text {rd }}$ year EDPM students thinking that they have enough awareness about leadership as they have taken courses on leadership, training and policy and the like. The reliability values were calculated to be 0.86 and 0.78 for perception items and expected challenges respectively. Next to this, orientation was given for participants of the study (trainees and instructors) regarding the overall intention of the study to make it ethical and to the point of intention. As the researcher himself was assigned instructor to teach one theme it was a good opportunity to dispatch and collect the data properly on time. So the pre-perception and expected challenges questionnaires were given in the first class day and the post test was given at the end of their training to collect the data needed based on the purpose of the study.

After collecting the pre and post test data SPSS version 24 was used to calculate the paired sample t-test to compare pre and posttest means using descriptive statistics and t- test value to identify whether there is significant different or not in between the two tests. In addition to this frequency count and percentage were used to analyze demographic information of both informants.

The interview data were collected using face to face communication with each the selected interviews. Narration and direct quote were used to analyze the response. The literatures were also reviewed and added to the findings of the data accordingly to support results gained. In addition the final report presented by trainees was collected form the coordinator and used as one source of data.

\section{Data Analysis, Presentation and Interpretation}

In this part the data collected from respondents are organized, presented and interpreted. Data were collected from primary sources from trainees at the beginning and at the end of the training and instructors involved in the training using questionnaires, interview and summary report of the training. The analysis is made to include general background of the respondents in the first part to look and show what types of respondents were participated in the study. In addition, in the questionnaires pre and post perceptions and views on school leadership including the perceived challenges are separately treated in the second part. Open ended item responses and interview results are also included to strengthen or support and substantiate the findings gained from questionnaires.

\subsection{General Background of Respondents}

To get complete and useful data randomly selected trainees $(\mathrm{N}=80)$ out of 117 were selected and 24 instructors involved in the training were taken as a target population of the study. From 117 trainees 93 randomly selected were participated in the study of which $80(86.02 \%)$ were retuned back by completing the questionnaire given to them as needed. Thus, the data collected from these 80 respondents were used for analysis. Regarding instructors, however 24 instructors were involved in the training, only 7 of them ( 1 from each of the thematic area) were taken to get data to the study through interview.

In general the general back ground of the respondents looks like the following.

\subsubsection{Respondents Regional and Zonal Address}

The regional and zonal addresses were collected to look their regional and zonal participation in the training. The reason to ask their address to know how far trainees come from different areas of the regions which will lead to the assumption the more they come from different areas the more they can share their prior experiences during their training on one hand regions and zones attention to send female trainees on the other hand.

Table 2: Trainees' regional and zonal distribution

\begin{tabular}{|l|r|r|l|r|r|}
\hline Region & N & \multicolumn{1}{|c|}{ Zones } & N & $\%$ \\
\hline Oromia & 55 & 68.8 & East harargie & 21 & 26.3 \\
\hline Harari & 13 & 16.3 & West harargie & 17 & 21.3 \\
\hline Diredewa & 12 & 15.0 & East shewa & 16 & 20.0 \\
\hline Total & 80 & 100.0 & West shewa & 1 & 1.3 \\
\hline & & & Harari & 13 & 16.3 \\
\hline & & & Diredewa & 12 & 15.0 \\
\hline & & & Total & 80 & 100.0 \\
\hline
\end{tabular}

As shown in table 2, 55(68.80\%) were from Oromia, and $13(16.3 \%)$ from Harari regions, and another 12 (15.00\%) from Dire dawa administrative city. Regarding their zonal distribution $21(26.30 \%), 17(21.30 \%)$, $16(20.00 \%)$ and $1(1.30 \%)$ were from East Harargie, West Harargie East Shewa, andWest Shewa zones of Oromiya region. Moreover, as Harari and Dire Dawa are not sub divided into zones 13 (16.30\%) trainees from Harahri and $12(15.00 \%)$ from Diredawa were participated in this study. This implies trainees were from different areas which 
will help them to share their experiences

\subsubsection{Trainees age and work experience}

School leaders need to have some experience in teaching before they become principals. Unless any obligatory situations are present any school principal should have at least 3-5 years of teaching experience. Thus to see whether trainees are in the required work experience data were collected and analyzed as follows.

Table 3: Trainees Actual Age and Work Experiences in Years

\begin{tabular}{|c|c|c|c|c|c|}
\hline Trainees age & $\mathrm{N}$ & $\%$ & Work experience & $\mathrm{N}$ & $\%$ \\
\hline 20-25 years & 27 & 33.8 & $<5$ years & 22 & 27.5 \\
\hline $26-30$ years & 32 & 40.0 & 6-10 years & 28 & 35.0 \\
\hline $31-35$ years & 8 & 10.0 & 11 to 15 years & 16 & 20.0 \\
\hline \begin{tabular}{|l|}
$36-40$ years \\
\end{tabular} & 11 & 13.8 & 16 to 20 years & 10 & 12.5 \\
\hline 41 and above & 2 & 2.5 & $>=21$ years & 4 & 5.0 \\
\hline Total & 80 & 100.0 & Total & 80 & 100.0 \\
\hline
\end{tabular}

As can be seen in table 3 respondents actual age and their work experiences are displayed based on specified categories. Respondents' age levels was dispersed from 20 to 41 and above that is categorized in to five labels and their respective experiences is shown side by side to see the correspondence between the two (age and experiences). The majority of trainees $32(40.00 \%)$ of respondents age is between $26-30$, followed by $14(15.10 \%)$ respondents are in age category of 20 -25. Regarding their experience 28(27.50\%) of respondents worked for 610 years and $22(27.50 \%)$ of them worked for less than five years. The rest $8(10 \%), 11(13.8 \%)$ and $2(2.5 \%)$ are in the age categories 31-36, 36-40 and greater than41 years of age. Moreover, $16(20 \%), 10(12.5 \%)$ and $4(5 \%)$ of the respondents were worked for 11-15, 16-20 and greater than 21 years respectively.

Form the respondents' age distribution and their experience distribution it is possible to see that as most of the respondents are in between of the total distribution. This implies that trainees were at proper age and work experience to lead schools as principals. There are extremes who are worked for 21 and above years which may be nearer to retirement because of their age is greater than 41 .

\subsubsection{Educational back grounds and trainees fields of study}

The other general information collected from respondents was respondent's educational level and their special field of study. The data related to this is reported as follows

Table 5: Trainees Educational Back ground and Special Field of Study

\begin{tabular}{|l|r|r|l|r|r|}
\hline Education level & \multicolumn{1}{|c|}{ F } & \multicolumn{1}{|c|}{ Field of study } & N & $\%$ \\
\hline BA degree & 79 & 98.8 & Languages & 34 & 42.5 \\
\hline MA degree & 1 & 1.3 & Social sciences & 15 & 18.8 \\
\hline Total & 80 & 100.0 & Natural sciences & 25 & 31.3 \\
\hline & & & Others( EDPM, management) & 6 & 7.5 \\
\hline & & & Total & 80 & 100.0 \\
\hline
\end{tabular}

Regarding the respondents' level of education and their special fields of studies are shown in table 5 above. As can be seen almost all respondents 79(98.8\%) are first degree holders. Only one of them is MA degree. In their field of study, 34(42.5\%), 15(18.8\%), 25(31.3) and 6(7.50) respondents are categorized under language, social sciences, natural sciences and others( EDPM and management) fields of studies respectively. From this it is possible to infer that trainees fulfilled the required level education to lead primary school however their fields of studies are not in line with school leadership except few of them who are EDPM and management.

\subsubsection{Trainees marital status}

Marital status of respondents may or may not have related to their leadership practices. In particular females are engaged in child care and house holding activities in our country Ethiopia that is why it is included as one of the concern in this study. Thus the data collected related to their marital status is reported as follows.

Table 6: Marital Status of Trainees

\begin{tabular}{|l|r|r|}
\hline Marital status & $\mathrm{N}$ & $\%$ \\
\hline married & 62 & 77.5 \\
\hline not married & 15 & 18.8 \\
\hline others & 3 & 3.8 \\
\hline Total & 80 & 100.0 \\
\hline
\end{tabular}

Respondents marital status as can be seen in table 6 above shows that $62(77.5 \%)$ are married, $15(18.8 \%)$ are not married and 3(3.8\%) of them are in others category may divorced or else. However, it is difficult to make judgment based on this data regarding their future leadership capacity and their perception towards leadership marital status might have direct or indirect influence actual leadership practices.

\subsubsection{Trainees prior participation in trainings}

Respondents were asked if they were participated in different related trainings or not before coming to this principal ship training. Responses collected from trainees are reported after the following table. 
Table 7. Trainees' participation in related prior training

\begin{tabular}{|l|r|r|}
\hline Trainees participation of prior related training & $\mathrm{N}$ & $\%$ \\
\hline yes & 18 & 22.5 \\
\hline no & 62 & 77.5 \\
\hline Total & 80 & 100.0 \\
\hline
\end{tabular}

As shown in table respondents were asked whether they participated in related training before they come to attend the present training or not. Based on this only $18(22.5 \%)$ of them were participated and the rest $62(77.5 \%)$ of them didn't participate in related prior training.

\subsubsection{Trainees selection modality for the training}

It is expected that trainees shall be selected through transparency to get the best candidates. Respondents were asked how they selected giving three options. The results obtained looks like the following.

Table 8: Trainees selection modality for the training

\begin{tabular}{|l|r|r|}
\hline Selection Modality & N & $\%$ \\
\hline Competitions with others & 53 & 66.3 \\
\hline By Higher officials without competitions & 25 & 31.3 \\
\hline I don't know how I am selected & 2 & 2.5 \\
\hline Total & 80 & 100.0 \\
\hline
\end{tabular}

To know how trainees were selected the selection modality employed before the come to the training were asked. In this regard three expected selection modalities (normal competitions, nomination without competitions, and no information regarding the selection were given for respondents. For this, $53(66.3 \%)$ of the trainees responded as they were selected through normal competitions with others, $25(31.3 \%)$ responded as the woreda higher officials selected them for the training and rest the $2(2.5 \%)$ explained as they didn't know how they were selected for the training. From this, what can be understood that as there was selection difference across different zones. This difference may have direct or indirect impact on their future leadership quality and effectiveness.

\subsection{Paired sample test results}

The main purpose of the study was to assess the impact of female leadership training offered for three consecutive months on the trainees' perception towards school leadership and their perceived challenges to leadership activities. Thus pre and post tests on both perception and perceived challenges were conducted (at the beginning and the end of the training). Based on these tests paired sampled t-test analysis is conducted and the results are reported as follows.

Table 7: Paired sample t-test of Trainees pre and post perception towards school leadership and perceived challenges

\begin{tabular}{|c|c|c|r|r|r|}
\hline \multicolumn{9}{|c|}{ Paired Samples Statistics } \\
\hline \multicolumn{2}{|c|}{} & Mean & $\mathrm{N}$ & $\begin{array}{c}\text { Std. } \\
\text { Deviation }\end{array}$ & Std. Error Mean \\
\hline \multirow{2}{*}{ Pair 1 } & Post training perception & 4.38 & 80 & .48 & .053 \\
\cline { 2 - 6 } & Pre training perception & 2.29 & 80 & .59 & .065 \\
\hline \multirow{2}{*}{ Pair 2 } & Pre training challenges & 3.63 & 80 & .56 & .062 \\
\cline { 2 - 6 } & Post training challenges & 2.22 & 80 & .66 & .074 \\
\hline
\end{tabular}

The paired sampled statistics table shows the mean and standard deviation values of both pre and posttests for perceptions towards leadership and perceived challenges to leadership activities. As indicated in this table the mean value for post training perception $(\mathrm{M}=4.38, \mathrm{SD}=0.48)$ is greater than the mean value for pretest perception $(\mathrm{M}=2.29, \mathrm{SD}=0.59)$. Moreover, the mean value of post training for perceived challenges $(\mathrm{M}=2.22, \mathrm{SD}=0.56)$ is less than the mean for post training perceived challenges $(\mathrm{M}=3.63, \mathrm{SD}=0.66)$.

Table 9. Paired sample t-test

\begin{tabular}{|c|c|c|c|c|c|c|c|c|c|}
\hline \multicolumn{10}{|c|}{ Paired Samples Test } \\
\hline & & \multicolumn{5}{|c|}{ Paired Differences } & \multirow[b]{3}{*}{$\mathrm{t}$} & \multirow[b]{3}{*}{$\mathrm{df}$} & \multirow{3}{*}{$\begin{array}{l}\text { Sig. (2- } \\
\text { tailed) }\end{array}$} \\
\hline & & \multirow[b]{2}{*}{ Mean } & \multirow[b]{2}{*}{ SD } & \multirow{2}{*}{$\begin{array}{l}\text { Std. } \\
\text { Error } \\
\text { Mean }\end{array}$} & \multicolumn{2}{|c|}{ 95\% Confidence } & & & \\
\hline & & & & & Lower & Upper & & & \\
\hline Pair 1 & $\begin{array}{l}\text { post training perception - pre } \\
\text { training perception }\end{array}$ & 2.09 & .75 & .08 & 1.92 & 2.26 & 24.85 & 79 & .000 \\
\hline Pair 2 & $\begin{array}{l}\text { pre training challenges - post } \\
\text { training challenge }\end{array}$ & 1.40 & .82 & .09 & 1.22 & 1.59 & 15.27 & 79 & .000 \\
\hline
\end{tabular}

As can be seen in the above table a paired-samples t-test was conducted to assess the impact of the female leadership training on trainee's perception towards school leadership and perceived challenges on leadership activities. There was a statistically significant increase in perceiving school leadership positively from pre training 
test $(\mathrm{M}=2.29, \mathrm{SD}=0.59)$ to post training $(\mathrm{M}=4.38, \mathrm{SD}=0.48), \mathrm{t}(79)=24.85, \mathrm{p}<0.05$ (two-tailed). The mean increase in pre-post training was 2.09 with a $95 \%$ confidence interval ranging from 2.29 to 4.38 .

Although the results presented above tell us that the difference we obtained in the two sets of scores was unlikely to occur by chance, it does not tell us much about the magnitude of the intervention's effect. One way to do this is to calculate an effect size statistic .To see effect size eta squared statistic was calculated using the formula: Eta Squared $\left(\eta^{2}\right)=\frac{t 2}{t 2+(N-1)}$

$$
\begin{aligned}
& =\left(\frac{(24.85) 2}{(24.85) 2+(80-1)}\right. \\
& =0.88
\end{aligned}
$$

The eta squared value of $\eta^{2}=0.88$ indicates that there was a large effect, with a substantial difference in the perception towards school leadership scores obtained before and after the training.

Regarding the perceived challenges there was statistically significant decrease in perceiving leadership activities in post training challenges $(\mathrm{M}=3.63, \mathrm{SD}=0.66)$ to pretest training challenges $(\mathrm{M}=2.22, \mathrm{SD}=0.56), \mathrm{t}(79)$ $=15.27, \mathrm{p}<0.05$. The mean difference between pre-post training challenges is $(1.40)$ with a $95 \%$ confidence interval ranging from 3.63 to 2.22 .

As that of the perception towards leadership eta squared was calculated to see the effect of the interaction between pre and post perceived challenges to leadership activities. The calculated eta squared is 0.75 which indicates large effect with the substantial differences between the pre and posttests.

\subsection{Data analysis from open ended items}

In addition to the questionnaires respondents were asked to explain their perception towards school leadership at the beginning of the training and at the end using open ended items.

One of the open ended questions raised at the beginning of the training was their expectations from the training. Most of the interviewees explained as they expect more from the training. They expected that the training can fill the gap related to leading school; the courses included in the training might be helpful and related to the actual school contexts, they also expect that the training develop their confidence to lead school.

In the second place they were asked about the gaps that the training might fill. In this regard, they responded that the training might fill problems that may encounter in their actual work place. Some of the gaps they listed were managing school finance, mobilizing community, increasing students' academic achievement and how to handle conflict in schools.

In the third place trainees were asked what they would be after completing the training. Most of the respondents were not able to explain this in brief but one of the interviewee explained as:

"When I get this opportunity I fill happy and I decided to do my best whatever challenges face me. Since now I believed that males are only leaders who are able to successfully lead organizations. But when I see different females leading in the higher positions I become eager to lead. Thus, I become best school leader after completing this training."

Another respondent also described as she will be skillful and knowledgeable to lead schools effectively. And they suggest that females should be encouraged form all sides of stakeholders to make them effective in every aspect, unless the only training may not lead to effectiveness.

\subsection{Interview data analysis}

Semi structured interview was held with selected trainees $(\mathrm{N}=5)$ not included to questionnaire respondents and 7 instructors assigned to give the training. In the following part the interview results are reported.

Instructors were interviewed in the around the end of the training. After some demographic characteristics (age, educational status, field of specializations, the theme assigned to train) of instructors were collected; the first interview item asked for instructors was about the necessity of the training. In this regard most of the interviewees explained that the training is necessary and it must be continuous. Two of the interviewees with similar explanation emphasize the necessity of the training. As to these interviewees females are competent to perform their task with caution and neatness. They are also strong, persistent and can take care of the community. Thus, the government started very important thing related to school leadership.

The second point was about trainees' readiness level, participation and interest towards the training and their future leadership position in schools. In this point most of the interviewees reported as most trainees were active participant in the training but few the trainees were reluctant because of different reasons (benefits during and after the training, child care, pregnancy).

The other point was the extent that the training minimizes cultural barratries such as stereotyping females as less effective in leadership position. They explained that the training can reduce what trainees have in their mind about themselves but awareness shall be created for other stakeholders beyond this training. They also reported that exemplary (model female leaders) should be used to motivate the trainees more and more.

The feelings of instructors in the overall the training was asked in the other part of the interview. They 
explained that taking part in the training made them happy except some administrative barriers facing them (eg. transportations, recreation). Some interviewees claim about the materials used for the training, the time allotted for the theme and the like. And they suggest that these challenges should be solved for the future.

The selected female trainees were interviewed as indicated above. The first point was about their perception towards school leadership. Related to their perception, they repeatedly mentioned that leadership is considered as the job given to males in most of the cases. That is why most females are not wanted to take part in leading positions. As to the interviews there are no encourage able practical activities to bring females towards leadership positions. Even the community believed that females are not capable of doing things right which is evidence based. Only some of the interviewees described as can do everything if they are supported by responsible bodies (government, the community, their family).

They mentioned some challenges they expect in leading positions. These are: lack of getting continuous training, lack of good leadership, improper handling of higher officials and lack of participation from stakeholders. They were asked to what extent the training solved these challenges. They described the training equipped them on manage resources (finance in school), develop confidence, knowledge, skill how to participate stakeholders, identifying successful and unsuccessful leadership features and to be good leader in the future.

Finally they explained some problems related to the training with possible suggestions. Assigning different instructors for course, lack of motivation after training (incentive), language problem ( it shall better to be in local language), timing problem, lack of commitment of some trainers ( time usage, not supportive, lack of preparation, carelessness, after training placement problems, lack of finance, lack of awareness in the community are selected challenges listed by interviewees.

In the end they suggestions that the training should be given for others in the school as well as educational leaders continuously, trainers as well as trainees should be committed, It should be given for higher officials and trainers should be selected carefully for the future (based on their performances ..., interest, knowledge, discipline.

\subsection{Trainees' final report}

Trainees report the overall accomplishment of the training and this report was used as one of the necessary data for this study. Some part of their report look like the following.

"... Before this training, almost all of us felt that leading, particularly schools, is too difficult for anyone except for those who have experiences in leadership. Most of us did not believe that we can have the ability to lead, the potential to overcome different challenges which rose in the school where we lead. To be frank, before taking this training, our perception towards leadership and management was not as such positive. This is because we had no more concept and knowledge about leadership. Sometimes we can think that leading is men's role and responsibility rather than for females...."

\section{Summary, Conclusions and Recommendations \\ 5.1 Summary}

The main objective of this study was assessing the impact of female primary school leadership training towards school leadership and perceived challenges on leadership activities. For this, 80 out of 117 female trainees and 7 out of 27 assigned instructors (trainers) were taken as sample of the study. Questionnaires (pretest and posttest) and interview were the main data collecting instruments. Questionnaire was used to collect data twice: at the beginning and at the end of the training to fit the intended objective. The results of the study looks alike the following.

\section{Demographic data results:}

To know the general background of the trainees their regional and zonal addresses, age and work experiences, educational level and special field of studies, marital status, prior training participation and trainees' selection modality were asked.

Regarding their regional and zonal distributions trainees were from three regions. Oromia sent 55(68.80\%) trainees from East Harargie, West Harargie East Shewa, and West Shewa zones and Harari sent 13 (16.3\%), and Dire dawa administrative city sent $12(15.00 \%)$. In relation to their age and work experiences as school leaders need to have some experience in teaching before they become principals trainees were from proper age and under the required work experiences. Most of the trainees were more than 25 years old and have experiences of 5 years and more.

The other general information collected from respondents was respondent's educational level and their special field of study. In this regard most of the trainees were first degree holder in different of the study. In addition their marital status was found some are married $62(77.5 \%), 15(18.8 \%)$ are not married and 3(3.8\%) of them are in others category may divorced or else. The result related to the presence of prior training only $18(22.5 \%)$ of them were participated and the rest $62(77.5 \%)$ of them didn't participate in related prior training. The selection modality employed to send trainees; $53(66.3 \%)$ of the trainees selected through normal competitions with others, $25(31.3 \%)$ were selected by woreda higher officials and rest the $2(2.5 \%)$ explained as they didn't know how they were 
selected for the training.

Regarding the trainers demographics all 3 are $\mathrm{PhD}$ holders and 4 are MAs in different fields of studies. They served for more than 4 years in the university and they have experiences in providing trainings.

\section{Data from the repeated measures (paired samples t-test)}

As the main purpose of the study was to assess the impact of female leadership training offered for three consecutive months on the trainees' perception towards school leadership and their perceived challenges to leadership activities pre and post tests on both perception and perceived challenges were conducted.

Thus, the mean value for post training perception $(\mathrm{M}=4.38, \mathrm{SD}=0.48)$ is greater than the mean value for pretest perception $(\mathrm{M}=2.29, \mathrm{SD}=0.59)$. Moreover, the mean value of post training for perceived challenges $(\mathrm{M}=2.22$, $\mathrm{SD}=0.56)$ is less than the mean for post training perceived challenges $(\mathrm{M}=3.63, \mathrm{SD}=0.66)$. A paired-samples ttest indicates that there was a statistically significant increase in perceiving school leadership positively from pre training test $(\mathrm{M}=2.29, \mathrm{SD}=0.59)$ to post training $(\mathrm{M}=4.38, \mathrm{SD}=0.48), \mathrm{t}(79)=24.85, \mathrm{p}<0.05$ (two-tailed). The mean increase in pre-post training was 2.09 with a $95 \%$ confidence interval ranging from 2.29 to 4.38 . The eta squared value of $\eta^{2}=0.88$ also indicates that there was a large effect, with a substantial difference in the perception towards school leadership scores obtained before and after the training,

Similarly, the perceived challenges there was statistically significant decrease in perceiving leadership activities in post training challenges $(\mathrm{M}=3.63, \mathrm{SD}=0.66)$ to pretest training challenges $(\mathrm{M}=2.22, \mathrm{SD}=0.56), \mathrm{t}(79)$ $=15.27, \mathrm{p}<0.05$. The mean difference between pre-post training challenges is $(1.40)$ with a $95 \%$ confidence interval ranging from 3.63 to 2.22 . Moreover, the calculated eta squared is 0.75 which indicates large effect with the substantial differences between the pre and posttests.

\section{Results from open ended items and reports}

Results from the open ended items and interview questions also support the results obtained from questionnaires. The perceptions of trainees towards school leadership and perceived challenges on leadership activities show improvement as compared to their entry to the training. As the exit report presented by trainees show that they develop confidence, capabilities of leading, problem solving skills and the like despite some challenges encountered in the process of training.

\subsection{Conclusions}

Females have numerous and significant importance for the development of a nation. Developing countries like Ethiopia shall involve females in every aspect of development activities if inclusive improvement is needed. The education sector needs females' active participation for the better handling of children. For this, bringing females to the front in leadership lines become mandatory. As this study indicates females consider themselves as inferior and cannot do leadership activities alone. But it is possible to change this wrong perception through trainings and provision of continuous support for females. Thus, perceptions towards school leadership can be improved through relevant training.

\subsection{Implications}

Based on the results obtained and conclusions made the following implications are forwarded.

1. Leading schools requires knowledge, skills and positive attitude to be effective. It is not a matter of being male or female to lead schools effectively, the only thing is being committed for the task and developing leading knowledge and skills. Thus, females have the capacity to lead regardless of their wrong perception guided by tradition over the past years which can be improved by trainings and self-development.

2. However females are capable to become a leader they need support from all sides of the community and the government. Thus lending them our hands should not be forgotten. Being aware of the possibilities that females can lead can reduce the challenge by half and if support by practice it will avoid the huge problem at all.

3. Perceptions highly affect practice, the more we perceive wrongly the less we preform practically. As can be ensured in this study wrong perceptions can be avoided through genuine training and continuous follow up. Thus, it shall better to train females to change their wrongly perceived out looks in leadership and related areas. The government, university trainers, program designers shall take this in to consideration.

4. Stakeholder collaborations shall be improved in different ways. Cultures and traditions showing as females are incapable of doing should be avoided with exemplary practices of females in the country as well as from the abroad.

\section{References}

Azzah, A. and Jones, K. (2017). An Overview of the Current State of Women's Leadership in Higher Education in Saudi Arabia and a Proposal for Future Research Directions. Journal of Administrative Science.

Busher, H. (2006). Understanding Educational Leadership: People, power and culture. England: Open University Press. 
Craig C., L. K. Donald \& H. Duglas. (1994). Sociology. 6th Edition, McGraw Hill Inc, Newyork: 277-285.

Giddens, A. (2005). Sociology, 4th Edition, Black Well Publishers, UK, 360- 361 \& 390-400.

Gold, A.(2000). Head of the Department: Principles in Practice. Great Britain: Redwood Books, Trowbridge, Wilts

Hoyle, E. and Wallace, M.( 2005). Educational Leadership:Ambiguity, Professionals and Managerialism. London:Sage Publications

Holtkamp, L.A. (2002). Advancing Women in Leadership; Crossing Borders: An Analysis of the characteristics and Attributes of Female Public School Principals. Texas, USA,1-9. Availableatwww.advancing. Women.com. http://www.un.org/womenwatch/daw/followup/session/presskit/fs1.htm. Accessed on March 22, 2018.

Leliftu M. (2014).Females Participation in Educational Leadership in Secondary Schools of Ilu Aba Bora Zone. Unpublished Master's Thesis, Jimma University. Department Of Educational Planning and Management, Jimma.

Lemessa G. (2014). Major Factors That Affect Female Teachers' Participation in School Leadership: The Case of Public Primary Schools in Jimma Town. Unpublished Master's Thesis, Jimma University, Department of Educational Planning And Management, Jimma.

Melero, E. (November, 2004). Sex Differences in Managerial Style: From Individual Leadership to Organisational Labour Relationships [Discussion Paper- No. 1387]. For schungs institut zur Zukunft der Arbeit Institute for the Study of Labor. Retrieved from

Ministry of Education( MOE).(2006). Decentralized Management of Education in Ethiopia. Ethiopia: Master Printing Press.

MOE. (2015). Education Sector Development Programme V (ESDP V) 2015/16 - 2019/20 G.C. Programme Action Plan. Ethiopia: Addis Ababa.

MOE.(2018).Training Guideline for Primary School Candidate Female principals. Unpublished

Ministry of Women's Affair(MOWA).(2006). Ethiopian Women Development and Change Package. Addis Ababa: National Printing Press Plc.

Netsanet W. (2013). Challenges and Opportunities of Women to be Leaders in Selected Governmental Secondary Schools of Addis Ababa. Unpublished Master's Thesis, Addis Ababa University, Institute of Educational Research and Development Addis Ababa, Ethiopia.

Nuri I. (2016). Primary Schools Personnels' Perception towards Female Teachers Repre- sentation on School Leadership Position in Guna Wereda, Arsi Zone of Oromia Regional State. Unpublished Master's thesis, Haramaya University, Haramaya .

Nzeli, K. (2013). Challenges Faced By Female Headteachers In The Management Of Secondary Schools: A Case Of Kangundo District In Machakos County, Kenya. Unpubulished Master's Thesis, Kenyatta University, The School Of Education, Kenya

Pele, S. (2012). The Role of Leadership in the Education System. Education Journal. Vol. 1, No. 1, 2012, pp. 58.doi: $10.11648 /$ j.edu.20120101.12

Pearman, S. E. E. ( 1999). Women in Educational Administration: Perspectives of the Rural Female Administrator. University of Alberta: A One-Credit Project Submitted to the Faculty of Education of the University of Lethbridge in Partial Fulfilment of the Requirements for the Degree.Unpublished.

Rimmer, J. (2003) .The four Dimensions of Instructional Leadership: What School Leaders Must Do to Improve Teaching Effectiveness, university of Washington, America. 